\title{
DA PESQUISA À SOLUÇÃO: PRODUÇÃO DE UM SISTEMA DE SINALIZAÇÃO INCLUSIVO
}

Fernanda Henriques, Dra

Universidade Estadual Paulista (UNESP)

ferdi@faac.unesp.com

Caio Henrique do Rosario Silva

Universidade Estadual Paulista (UNESP)

Cassia Leticia Carrara Domiciano, Dra

Universidade Estadual Paulista (UNESP)

cassiacarrara@gmail.com
Danielle Naomi Nakatsu

Universidade Estadual Paulista (UNESP)

Gleisson José Dos Santos Cipriano

Universidade Estadual Paulista (UNESP)

gleissonjose@gmail.com

Mariana Shizue lamaguti

Universidade Estadual Paulista (UNESP)

marianaiamaguti@gmail.com

Resumo: O campus da Universidade Estadual Paulista (Unesp), em Bauru, interior de São Paulo, recebe, aproximadamente, 8.000 pessoas por dia. A falta de uma sinalização no local era evidente e, após questionário aplicado à comunidade do campus constatou-se que o sistema existente era deficitário, inapropriado e fazia com que muitos se sentissem desorientados. Neste artigo apresentaremos o processo investigativo realizado sobre design da informação, design gráfico ambiental e design inclusivo, princípios norteadores da criação e produção de uma inovadora sinalização para o campus de Bauru, ainda em desenvolvimento pelo laboratório de pesquisa e extensão Inky Design e do Grupo de Pesquisa Visão, Audição e Linguagens.

Palavras-chave: Design Inclusivo; Design Gráfico Ambiental, Sinalização, Wayfinding, Daltonismo.

\begin{abstract}
The campus of the Universidade Estadual Paulista (Unesp), in Bauru, interior of São Paulo, receives, approximately, 8000 people every day. The lack of signage on the place is very clear and after applying a questionnaire to the campus' community, was observed that the existent system was deficitary, inappropriate and great contributor to the user's misorientation. In this article, we are going to present the investigative process executed upon information, inclusive and ambiental graphic design, the guiding principles to the concept and production of an innovative signage system for the campus of Bauru, which still in development by the laboratory of research and extension Inky Design and the Group of Research on Vision, Hearing and Languages.
\end{abstract}

Keywords: Inclusive design; Ambiental Graphic Design; Signaling; Wayfinding; Daltonism. 


\section{INTRODUÇÃO}

O campus de Bauru, antiga Universidade de Bauru, que foi incorporada pela Universidade Estadual Paulista "Julio de Mesquita Filho" em agosto de 1988, possui uma área total de 456,68 hectares, com 71.087,52 $\mathrm{m}^{2}$ de área construída - salas de aulas, laboratórios, biblioteca, departamentos de ensino e áreas administrativas. É o maior campus da instituição, abrigando três faculdades e uma administração geral. Em torno de 8.000 pessoas passam pelo local diariamente, entre servidores, docentes e discentes. Além disso, por se tratar de um espaço público, a população da cidade e eventuais visitantes de outras cidades, estados e países utilizam os serviços presentes no campus, como auditórios, praça de esportes, bancos e projetos de extensão voltados à comunidade. A geografia do campus de Bauru se estende por ruas, calçadas, avenidas, bosques e, inclusive, uma estrada estadual, fazendo com que pedestres convivam com os mais diversos meios de locomoção. Em virtude da complexidade e extensão do campus, a sinalização atualmente aplicada carece de informações em pontos importantes além de sofrer com a falta de unidade visual das mensagens. Outro ponto negativo diagnosticado foi a presença de placas degradadas não só devido ao vandalismo e intempéries como também por problemas técnicos de materiais e impressões que não levaram em conta o clima da cidade. Todas essas questões colaboram com a dificuldade das pessoas em movimentarem-se de maneira segura dentro do espaço universitário.

O projeto vem sendo desenvolvido desde maio de 2015, dentro do laboratório Inky Design e do grupo de pesquisa Visão, Audição e Linguagens, promovendo a tríade da universidade - ensino, extensão e pesquisa. Seguindo a metodologia proposta por Cardoso et al. (2014), dividiu-se o projeto em três fases, sendo a primeira o levantamento do problema frente às teorias adotadas (design inclusivo, de produto, wayfinding, design gráfico ambiental), unindo-o às pesquisas bibliográficas e de campo (questionários para levantamento de problemas e testes de resultado). A segunda fase contemplou esboços, criação de layouts e protótipos, e a realização de testes com daltônicos e pessoas de baixa visão. Todo o resultado da criação agora compõe o manual visual do projeto. A terceira etapa do projeto incluiu o desenvolvimento de manuais técnicos e de produção, partindo-se então para a implementação, que se iniciará ainda em 2016 e deverá contar com o envolvimento de alunos dos cursos de Engenharia Civil, Engenharia de Produção e de Arquitetura e Urbanismo da própria Unesp.

Devido à setorização já existente do campus por meio de cores específicas para cada unidade, foi necessário utilizar um sistema de identificação de cores por meio de símbolos, o que tornará o ambiente acessível também para daltônicos. Além disso, todo o projeto gráfico foi feito levando em consideração a inclusão de pessoas com diversas capacidades visuais. Essas iniciativas são essenciais para que se tenha não apenas um sistema acessível, mas também mais humano e inovador.

\section{OBJETIVOS}

O objetivo do projeto foi o desenvolvimento de uma sinalização coerente, unificada e inclusiva para o campus de Bauru, considerando-se todas as questões inerentes a este fim, como fluxo de usuários, condições de uso por pedestre e veículos, 
acesso à informação e identidade visual da universidade e faculdades envolvidas. Para esse artigo, focamos nas relações entre a pesquisa teórica em áreas do conhecimento relevantes, a pesquisa de campo e a obtenção de um resultado projetual coerente, forte e eficiente.

\section{FUNDAMENTAÇÃO TEÓRICA}

Foi fundamental para o desenvolvimento do projeto a busca de uma conceituação mais profunda a temas relevantes ao escopo do trabalho. Mostrou-se de extrema importância entender o papel da sinalização e o processo de wayfinding nos espaços públicos, e, não menos relevante, compreender como um projeto nesse tipo de ambiente necessita contemplar todos os usuários da melhor forma possível.

Segundo Cardoso et al (2014, p.11), design gráfico ambiental, ou apenas design ambiental, é uma área multidisciplinar, que atua na intersecção do design gráfico, design de produto, arquitetura e paisagismo. Além dessas disciplinas, também abrange questões de identidade visual, sinalização e wayfinding, sendo estas duas últimas, muitas vezes, entendidas como sinônimos, devido à quantidade de significados que o termo sinalização pode ter.

Sinalização pode ser entendida das mais diferentes maneiras. Uma dobra ou marca feita a lápis no canto de uma página é um sinal, logo, uma sinalização. Ademais, podemos dizer que sinalização pode também ser usada para representar qualquer superfície física que, de alguma forma, possui uma informação que ajude alguém a se localizar (VELHO, 2007, p.47). Por outro lado, entendemos wayfinding como uma solução onde pessoas podem se locomover, por exemplo, do ponto $A$ ao ponto $B$, $e$ voltar para ponto A sem se perder no meio do caminho. A sinalização, nesse contexto, é uma ferramenta do wayfinding, que Arthur e Passini (2002 apud SMYTHE, 2014, p.13) definiram como:

[...] um sistema de auto-localização referente ao entendimento do comportamento humano em saber onde está, para onde ir, fazer escolhas sobre a melhor rota para chegar ao seu destino, reconhecer quando chegou ao seu destino e conseguir fazer o caminho inverso encontrando o caminho de volta.

Como citado previamente, o projeto de Design pode ser entendido como a resposta anterior para um problema, por meio de soluções criativas na concepção, elaboração e criação, tendo-se sempre em mente os objetivos, funções, utilizações e relação do utilizador com o produto projetado (MACHADO, 2006). Assim, designers necessitam conciliar as questões das diferenças físicas, sociais e culturais ao processo do design, selecionando e aperfeiçoando os métodos projetuais mais adequados para o desenvolvimento de determinado produto.

O design deve ajudar as pessoas e as comunidades a prepararem-se para $\mathrm{o}$ futuro, assim como deve contribuir para melhorar a qualidade de vida no presente. Projectar com inclusividade significa incluir as pessoas que normalmente poderiam ser ignoradas no processo de design (PINHEIRO e SILVA, 2010, p.68). 
Dessa forma, ao considerar a inclusão de um maior número de pessoas no seu escopo de usuários, o designer visa o benefício destes tanto como indivíduos quanto como coletividade, proporcionando ambientes mais democráticos, justos e flexíveis, gerando independência física e emocional, aumentando a autoestima e a dignidade das pessoas. Entender, portanto, os conceitos de design inclusivo e universal foi outro ponto importante na busca por conceitos que norteassem o processo projetual.

Design Universal é um termo usado nos Estados Unidos, enquanto na Europa se usa Design for All ou Design Inclusivo; os princípios para a sua implementação são semelhantes: Facilitar o uso de produtos e serviços para todos os utentes, e assegurar que as necessidades, os desejos e as expectativas dos utilizadores são tidos em consideração no processo de design, e na avaliação dos produtos e serviços (PINHEIRO e SILVA, 2010, p.69)

Enquanto o conceito de design Universal é usado para designar um projeto para todos, sem nenhum tipo de diferenciação, o termo Design inclusivo ganha força nas pesquisas brasileiras, focando-se no design para um maior número de pessoas possível. Segundo Barbara Silverstone (apud Pinheiro e Silva, 2010, p. 69), é necessário "incluir princípios de design gráfico universal em todos os meios visuais para que sejam verdadeiramente úteis e legíveis para o maior número possível de pessoas. A comunidade de designers gráficos tem sido mais lenta na adoção de princípios de design inclusivo".

Incluir pelo design exige diversas preocupações visto que os usuários são plurais. A inclusão em um projeto de sinalização deve considerar fatores como legibilidade, visibilidade, cores, disposição de elementos, proporções, enfim, acesso físico e visual à informação. Portanto, além dos conceitos mais abrangentes como wayfinding, design ambiental e design inclusivo, foi necessária a pesquisa em torno de questões mais específicas, que abordassem pontos peculiares do projeto. $O$ uso de cores foi um deles.

Diante da pesquisa bibliográfica e de levantamento realizado no campus mediante diversas ferramentas e procedimentos, procurou-se localizar soluções possíveis para os problemas encontrados. Devido à falta de coesão gráfica e a ausência de uma sinalização eficiente, notou-se que a aplicação da teoria de design gráfico ambiental seria o caminho para se atender às exigências apontadas. Para chegarmos no melhor resultado, teríamos de pensar no local sendo acessível pela maior quantidade de pessoas possíveis, com variadas limitações e deficiências. Nessa perspectiva, os projetos devem incluir o maior número de pessoas, pensando o local em sua totalidade (ruas, prédios, oficinas, bosques, etc.) acessível e de fácil utilização. Projetar, na atualidade, deve, portanto, implicar em "(...) criar algo que a todos sirva" (MACHADO, 2006).

\section{METODOLOGIAS DE PESQUISA E PROJETO}

O projeto desenvolvido baseou-se na metodologia de Cardoso et al. (2014, p.27) para o desenvolvimento de sinalizações. O projeto foi organizado em fases, a saber: 


\subsection{Planejamento (briefing e levantamento de dados)}

Essa fase teve início no contato feito pelas diretorias das faculdades presentes no campus com as professoras orientadoras do projeto de pesquisa e extensão Inky Design. Depois, com a equipe composta por alunos da graduação do curso de Design, foi feito o levantamento de dados referentes às problemáticas, buscando os motivos que faziam as pessoas se perderem assim como todos os fatores que tornam o campus um lugar de difícil locomoção. Ademais, levantamento bibliográfico sobre conceitos ligados à sinalização, projetos inovadores e deficiências foram incluídos. Uma estratégia importante neste momento do projeto foi somar à equipe uma aluna de Iniciação Científica, que complementou o trabalho com as pesquisas referentes ao daltonismo e os sistemas de identificação de cores como o ColorADD e o Feelipa Color Code.

\subsection{Projeto: Pesquisa, desenvolvimento e detalhamento}

Após as definições metodológicas iniciais, partiu-se para a geração de alternativas gráficas, seguindo o levantamento feito na fase anterior. Definições como formas, proporções, cores a serem empregadas nas placas, contraste entre elementos, escolhas tipográficas e a estética dos pictogramas foram testadas junto aos usuários do próprio campus. Este grupo incluiu alunos, funcionários e público externo, sendo eles portadores de daltonismo e baixa visão ou pessoas consideradas visualmente saudáveis (grupo de controle). As críticas feitas pelos usuários nesses testes pautaram as alterações realizadas para a produção do manual visual, imprescindíveis para possibilitar a implementação do projeto.

\subsection{Implementação (Orçamento, produção e implementação)}

A fase seguinte, com início em julho de 2016, inclui o desenvolvimento de manuais técnicos, definições de materiais e realização de orçamento detalhado para abertura de licitação. Depois disso, deve-se supervisionar toda a fase de produção e implementação da proposta, realizando, também, um acompanhamento para saber se o projeto desenvolvido está atendendo ao público.

\section{DESENVOLVIMENTO}

Após a pesquisa preliminar, os primeiros esboços e layouts possibilitaram a produção de mockups em tamanho real, que foram testados junto a uma amostra de usuários. O resultado destes testes geraram novos ajustes e correções, permitindo um resultado final consistente e eficaz. A seguir, detalhamos cada uma dessas etapas.

\subsection{Pesquisa de campo preliminar}

O problema supostamente apresentado pela sinalização atual do campus foi constatado e confirmado logo no início do processo, junto ao publico usuário do sistema. Um questionário on-line foi enviado para todos, cuja participação foi prontamente recebida, tanto por docentes e discentes, quanto por funcionários. Com isso, obteve-se um panorama detalhado da situação através das respostas. 


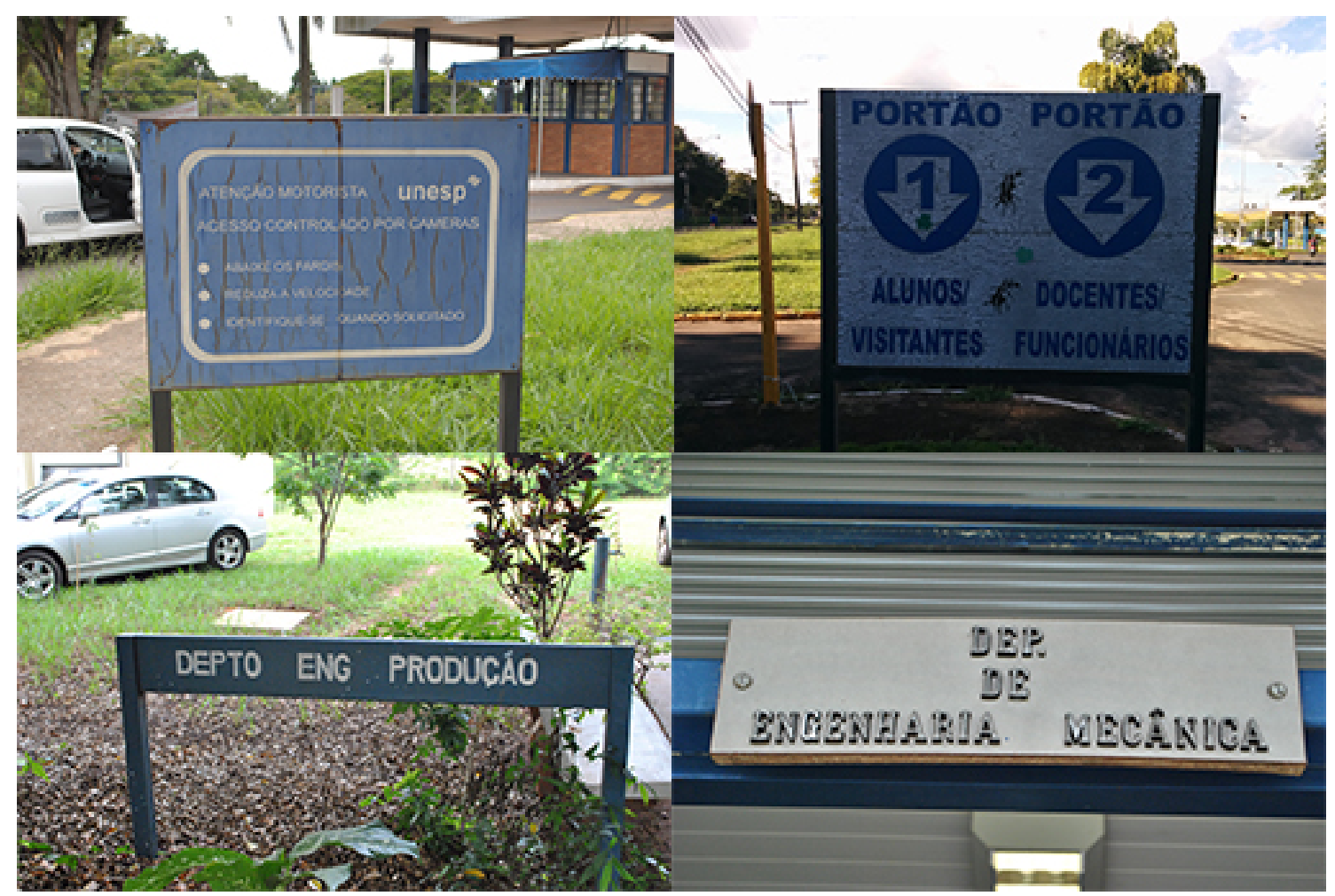

Figura 1 - Atual sinalização do campus.

Fonte: Elaborado pelos autores, com base na pesquisa realizada.

\subsection{Formatos}

Verificou-se a necessidade do desenvolvimento de quatro tipos principais de totens de sinalização:

A- Totem com mapa completo de todo o perímetro do campus, com informações detalhadas como laboratórios, portarias, bolsões de estacionamento, etc.

B- Totem para pedestres, com informações e tamanhos relevantes;

C- Totem para pedestres com um mapa em zoom, contendo informações mais completas, como projetos de extensão, salas de aula, laboratórios, etc.;

D- Totem para automóveis, com informações relevantes para veículos motorizados, como bolsões de estacionamento, saída, anfiteatros, etc.;

\subsection{Tipografia}

Procurando uma tipografia desenvolvida especificamente para projetos de sinalização, decidimos que a melhor maneira de fomentarmos o mercado nacional de fontes era escolhendo uma tipografia brasileira. A Guanabara Sans, desenvolvida pelo estúdio carioca Plau Design, foi projetada pela necessidade de uma fonte para wayfinding pensada para ser utilizada em cidades. Inspirada pelas curvas do Rio de Janeiro, ela possui a gama de opções e pesos necessários para o desenvolvimento de um projeto de design gráfico ambiental como o que vem sendo desenvolvido para Unesp Bauru. 


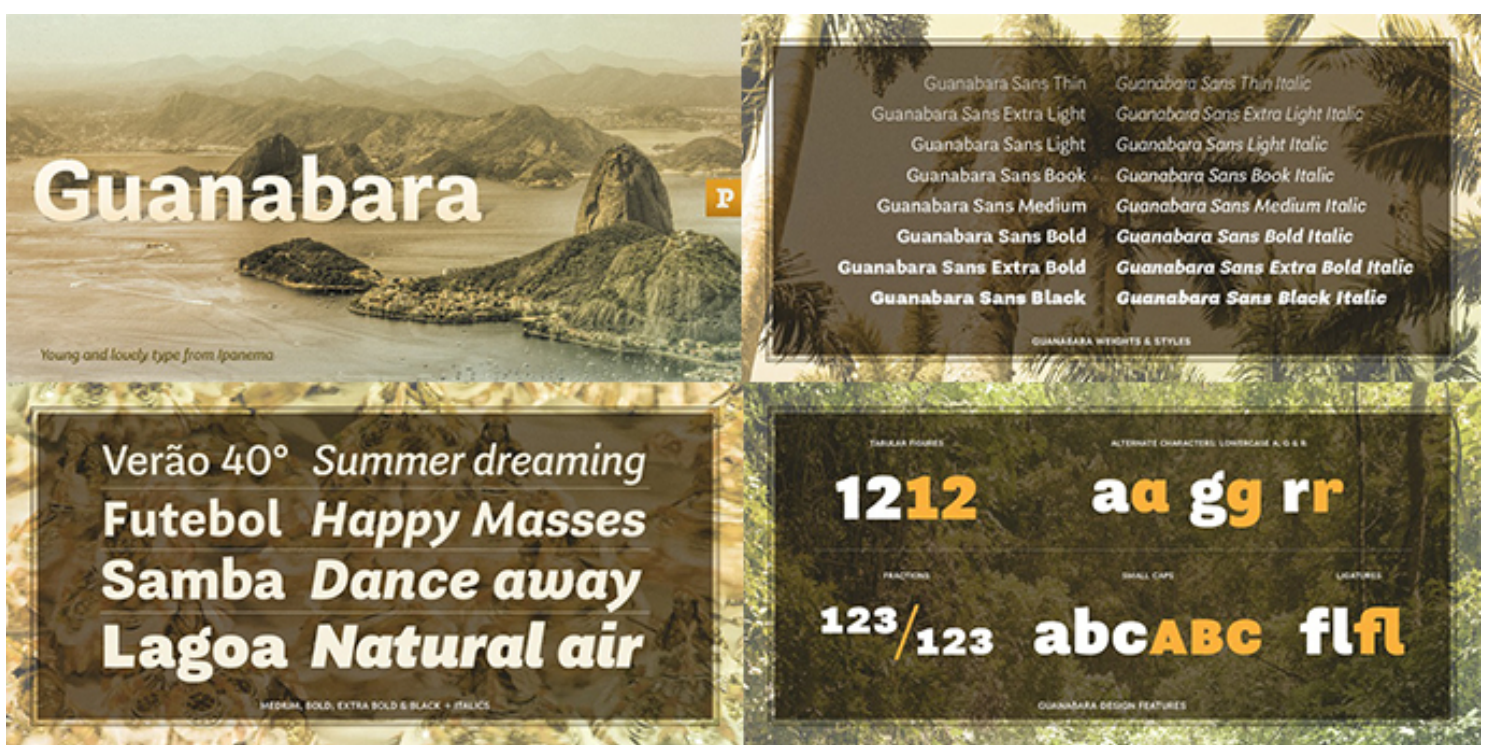

Figura 2 - Specimen sheet da Guanabara Sans.

Fonte: Adaptado de: MyFonts.com.

\subsection{Cores}

A cor, por representar grande parte das reproduções visuais absorvidas, auxilia na diminuição do tempo de reação à uma mensagem. Ela é ainda responsável por organizar, impressionar, expressar e construir informações, transmitindo ideias, aumentando a eficiência da mensagem, chamando e direcionando a atenção e enfatizando a informação (FARINA, RODRIGUES \& FILHO, 2006 apud MAIA, 2012, p.41). Desta maneira decidiu-se por definir as áreas das respectivas faculdades pertencentes ao campus da Unesp com suas cores institucionais: Vermelho para a Faculdade de Artes, Arquitetura e Comunicação (FAAC), verde para a Faculdade de Ciências (FC), azul para a Faculdade de Engenharia (FEB) e por fim, para a administração geral, foi escolhido o amarelo.

Considerando a escolha das cores apropriadas para o design inclusivo, as tonalidades das referidas cores ganharam uma atenção especial, uma vez que essas cores são as que geram mais dificuldades para os daltônicos (verde/vermelho para casos de protanopia e deuteranopia, azul/amarelo para tritanopia). Como solução, foi avaliado o contrate existente entre esses pares de cores de maneira que a saturação ou intensidade entre estas seja diferente. Como já citado, para contemplar ainda mais aqueles que são portadores de anomalias da visão, propôs-se utilizar um sistema de identificação de cores por meio de símbolos. O primeiro sistema testado foi o ColorADD $^{\circledR}$, que consiste em um conjunto de símbolos monocromáticos de representação de cores, voltado aos daltônicos, a fim de sanar as dificuldades de identificação advindas dessa anomalia.

\subsection{Mapas}

O campus de Bauru, como citado, possui uma área total de 456,68 hectares, com 71.087,52 $\mathrm{m}^{2}$ de área construída. Por ser extenso, a existência de um mapa é de suma importância para atingir o objetivo do wayfinding: facilitar a locomoção individual dos usuários. Para isso, foi desenvolvida uma representação detalhada do campus, com a possibilidade de utilizá-lo em versões em close, mais próximas em 
determinados locais. Com isso, possibilitamos aos usuários uma melhor localização no espaço como um todo.

\subsection{Testes de legibilidade e funcionalidade das placas}

Como parte do intuito do projeto - desenvolver um design gráfico ambiental inclusivo, utilizando-se do tripé fundamental da universidade - a realização de testes com pessoas com alguma deficiência visual e, também, com pessoas saudáveis (grupo de controle) foi imprescindível para concluirmos se nossas pesquisas e soluções visuais estavam de acordo com o ideal do projeto. Foram realizados dois testes. O primeiro, efetuado no mês de março de 2016, contou com 10 pessoas de grupo de controle (sem nenhum tipo de deficiência visual). Este teste foi utilizado para aprimorar as perguntas, verificando se estavam funcionando e se todas as placas ali dispostas ao teste dos usuários eram realmente necessárias.

O segundo, realizado por todo mês de abril, contou com o total de 44 entrevistas, dentre as quais, 11 dos sujeitos tinham algum tipo de deficiência visual ( 7 pessoas com daltonismo, 2 com baixa visão e 2 com retinose pigmentar). Neste segundo teste, foram feitas alterações nas artes de algumas placas, bem como no questionário de forma geral, adicionando, excluindo, reordenando e mesclando questionamentos até chegamos nos resultados desejados.

Em ambos os testes, utilizou-se de modelos em tamanho real. Placas de foam board e impressão em plotagem rápida das artes foram os meios utilizados para a confecção dos mesmos. Com isso, tivemos a possibilidade de fazer testes acurados, onde os participantes puderam responder com a máxima exatidão as perguntas propostas.

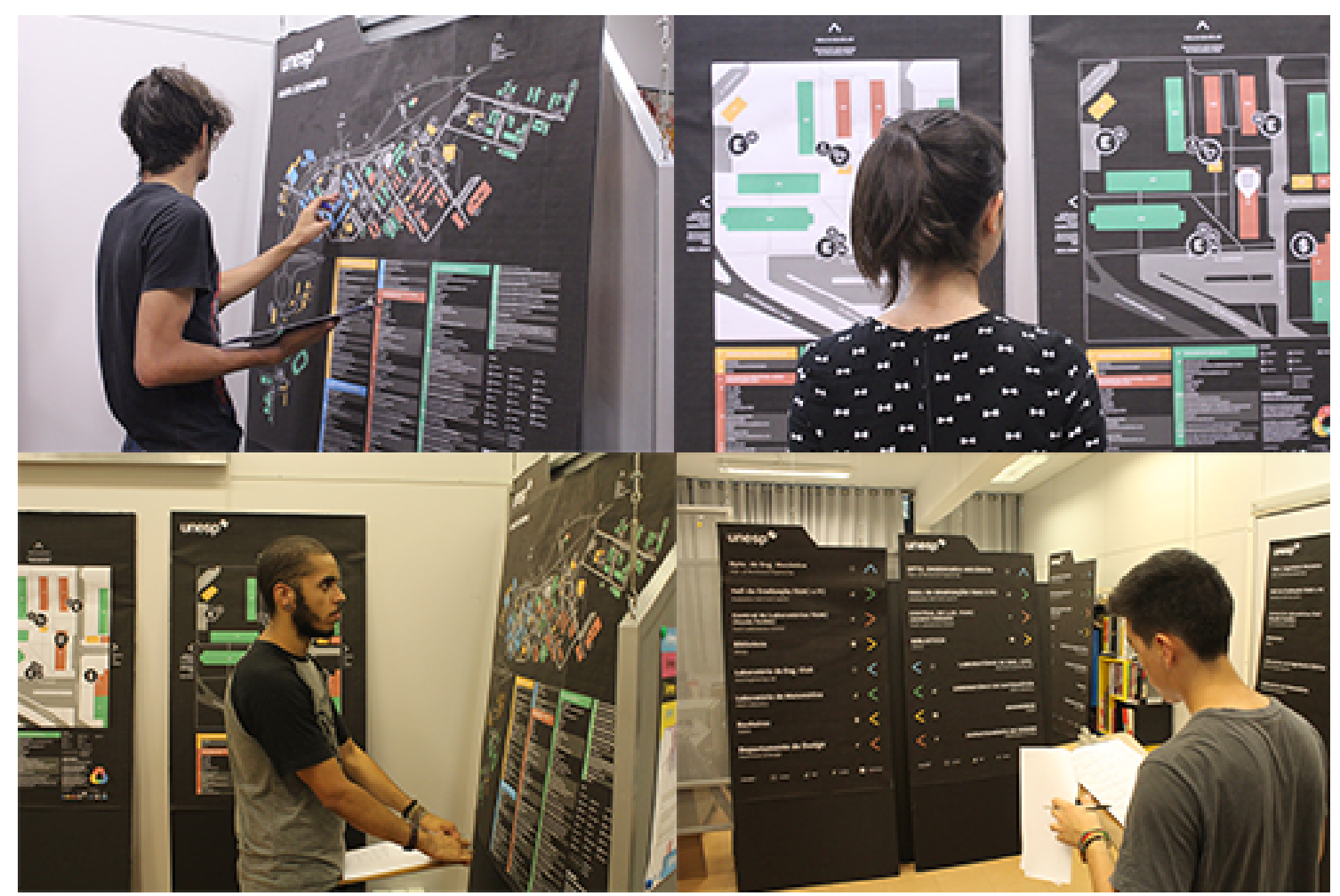

Figura 3 - Fotos dos testes realizados.

Fonte: Elaborado pelos autores, com base na pesquisa realizada. 
Ao final de cerca de dois meses de testes, conseguimos vislumbrar se as soluções propostas estavam sendo, de fato, funcionais. O feedback dos usuários pautou as alterações realizadas para a produção dos manuais visuais e técnicos do sistema de sinalização, assim como, nos ajudaram a repensar a necessidade de algumas soluções além das já propostas. Com isso, vimos que para produzir um design gráfico ambiental inclusivo é de extrema necessidade não apenas métodos empíricos, de tentativa e erro, mas também científicos.

Observamos que nos totens para pedestres e para veículos as setas direcionais funcionam melhor se forem intercaladas, algumas na direita, outras na esquerda. Também concluímos que, no totem para automóveis, a tipografia funciona muito melhor em caixa alta, enquanto que, no de pedestres, Sentence case é preferível, além de funcional.

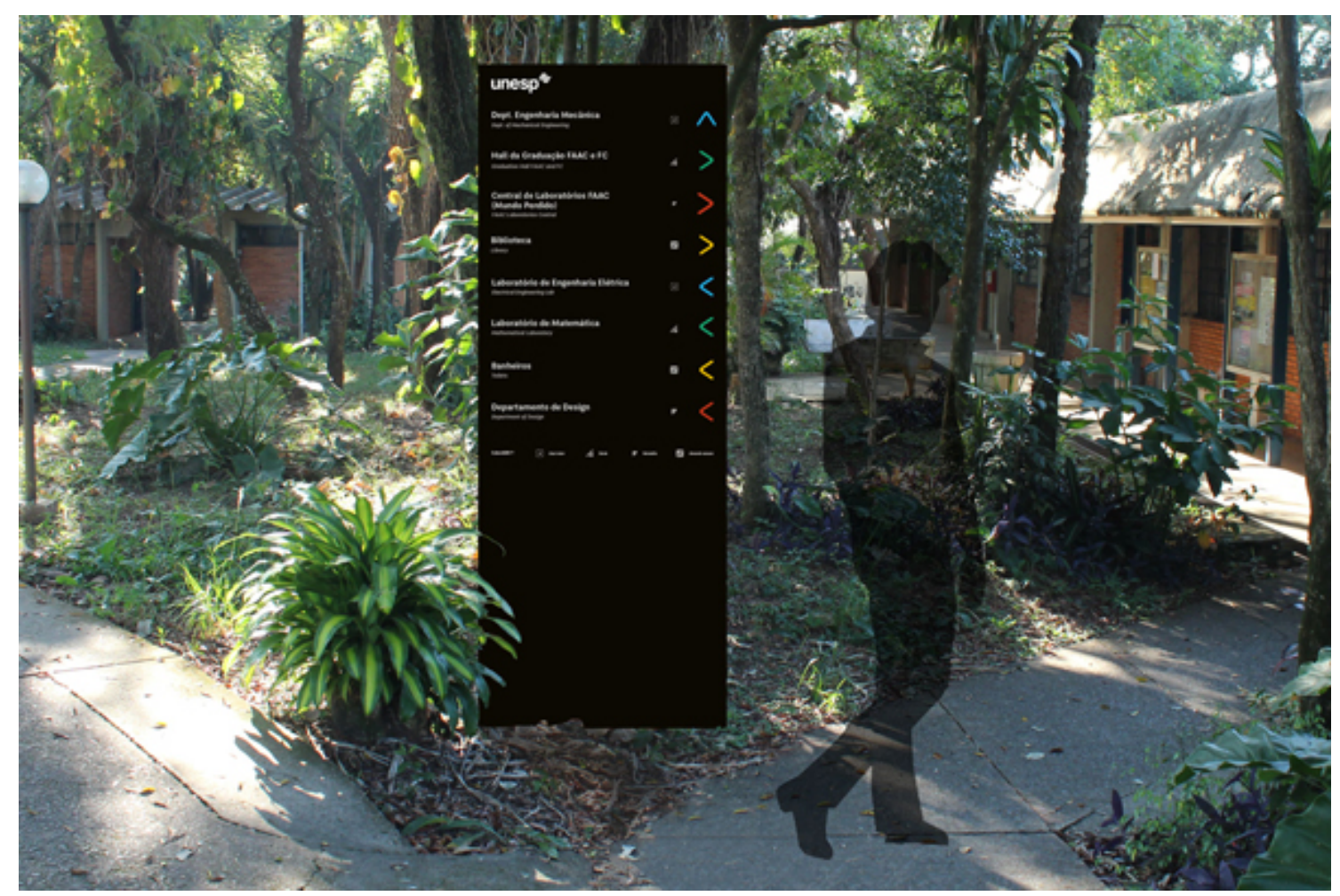

Figura 4 - Simulação digital das placas de pedestre.

Fonte: Elaborado pelos autores, com base na pesquisa realizada.

No mapa informacional do campus, o tamanho das legendas foi muito questionado. Ademais, sentimos que este mapa poderia ter uma liberdade maior a respeito das proporções de ruas e prédios, principalmente diminuindo algumas regiões onde a circulação de pessoas é reduzida. 


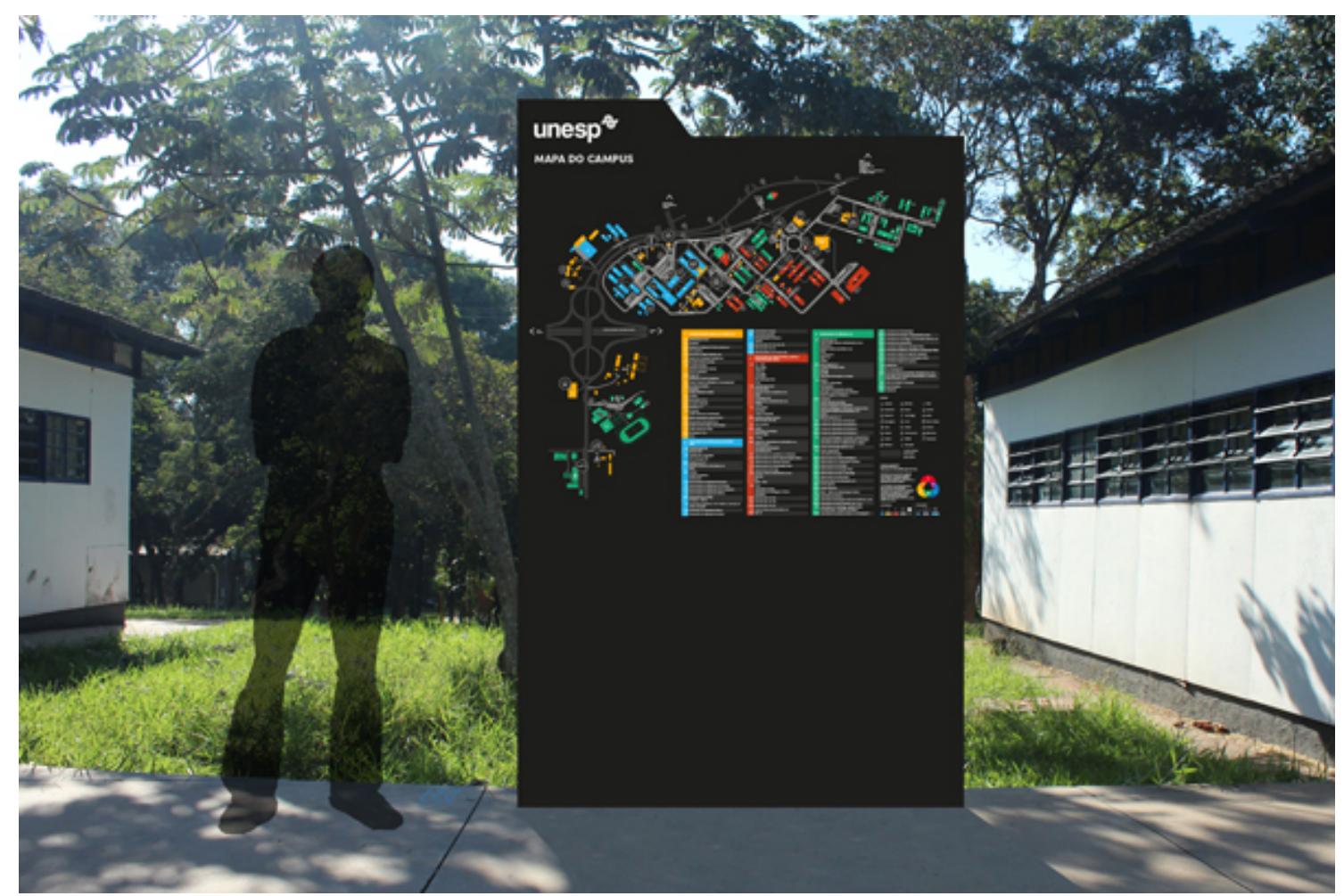

Figura 5 - Simulação digital do totem com o mapa do campus.

Fonte: Elaborado pelos autores, com base na pesquisa realizada.

Nos testes com pessoas com alguma deficiência visual, encontramos problemas com as cores escolhidas. O espectro tonal dificultava o entendimento das cores por parte dos daltônicos. Decidimos, então, utilizar o "Color Universal Design" (Design Universal de Cor), usando cores perceptíveis tanto para as pessoas com problemas de percepção de cores quanto para as que não possuem nenhuma anomalia (EIZO, 2006, p.4). O sistema de identificação de cores utilizado mostrou-se eficiente junto ao público daltônico, porém numa pesquisa mais completa sobre sistemas desta natureza, optou-se pelo uso de outro projeto, o Feelipa, código de cores desenvolvido por Filipa Nogueira Pires (www.feelipa.com) que além da representação cromática ser por meio de símbolos, também possibilita aplicação em relevo dos mesmos, o que incluiria e beneficiaria também os deficientes visuais na identificação das cores das três faculdades representadas. De qualquer forma, as duas soluções contemplariam o desenvolvimento de um projeto acessível para todos.

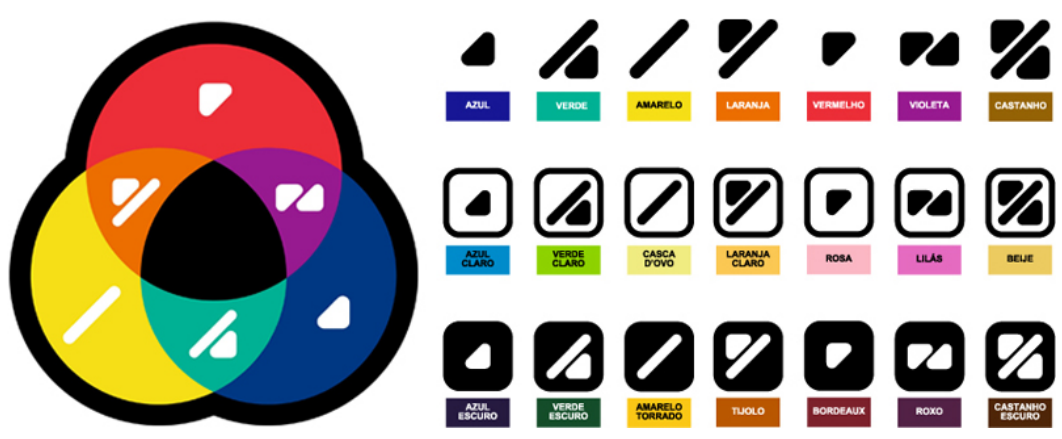

Figura 6 - Sistema de cores para daltônicos ColorADD ${ }^{\circledR}$. Fonte: Adaptado de designine9.blogspot. 


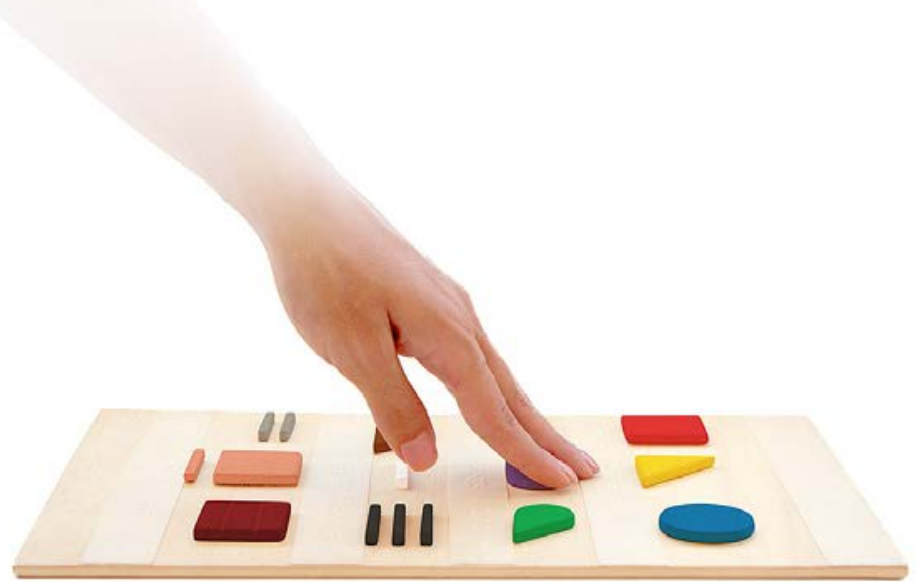

Figura 7 - Sistema de cores para cegos e daltônicos Feelipa.

Fonte: Adaptado de Feelipa.com

\section{CONSIDERAÇÕES FINAIS}

Como resultados deste projeto, professores e alunos envolvidos esperam oferecer à Unesp um design gráfico ambiental inclusivo competente e, aos usuários, uma sinalização de qualidade, que a todos inclua, e instigue a exploração e melhor locomoção pelo local. Outro ponto de destaque neste trabalho é a possibilidade de implementação dessa solução em outros campi da Unesp, que conta com 34 unidades em 24 cidades, sendo 22 no interior, uma na capital e uma no litoral sul do Estado de São Paulo.

Uma outra qualidade do novo sistema é ser inovador e inclusivo. A inclusão de pessoas com algum tipo de deficiência tem sido um grande desafio para o projeto. Além do uso do sistema de cores para daltônicos, a altura das placas, tamanho das letras, contraste de cores, enfim, as soluções visuais geradas, buscam externar uma instituição mais humana e acessível aos olhos da comunidade.

\section{AGRADECIMENTOS}

Agradecemos à A Fundação de Amparo à Pesquisa do Estado de São Paulo (FAPESP) pelo apoio.

\section{REFERÊNCIAS}

ARTHUR, P. e PASSINI, R. Wayfinding-People, Signs, and Architecture. New York: McGraw-Hill, 2002.

CARDOSO, SCHERER, TEIXEIRA, SILVA \& SILVA. Contribuição metodológica em design de sinalização. InfoDesign, v. 8, n. 1, p. 10 - 30. São Paulo, 2011. Disponível em: <http://www.infodesign.org.br/infodesign/article/view/107/107>. Acesso em 20 Abr. 2016.

EIZO - Color Universal Handbook (2006). Disponível na internet por http em: $<$ http://www.eizo.com.tw/products/flexscan/color_vision/handbook.pdf>. Acesso em 20 Abr. 2016. 
MACHADO, Ana Margarida Almeida. Introdução ao conceito de design inclusivo: Aplicações práticas em desenho urbano e equipamentos sociais/saúde. Portugal, 2006. Disponível na internet por http em: <http://www.segsocial.pt/documents/10152/51688/Design_inclusivo/450a4d29-a006-4518-a41551f8edbf0b18?version=1.0> >. Acesso em 20 Abr. 2016.

MAIA, Amanda Fortes Dalla Valle Majó da. Representação gráfica de mapas para daltônicos: Um estudo de caso dos mapas da rede integrada de transporte de Curitiba. 2013. Tese. Universidade Federal do Paraná. Curso de pós-graduação em Design. Disponível na internet por http em: http://docplayer.com.br/17092659Representacao-grafica-de-mapas-para-daltonicos.html. Acesso em junho de 2016.

PINHEIRO, M.C. SILVA, F. M. Comunicação Visual e Design Inclusivo:Cor, legibilidade e visão envelhecida. In SILVA, J. C. P.PASCHOARELLI, L. C. SILVA, F. M. Design Ergonômico - Estudos e Aplicações. Bauru: FAAC - Universidade Estadual Paulista, 2010 SMYTHE, K. C. A. da S. Inclusão do usuário na fase inicial do processo de design para sistemas de wayfinding aplicados a ambientes hospitalares já construídos. MA Design. Universidade Federal do Paraná, 2014. Disponível na internet por http em: <http://acervodigital.ufpr.br/handle/1884/36163>. Acesso em 20 Abr. 2016.

VELHO, A. L. de O. L., 2007. O Design de sinalização no Brasil: A introdução de novos conceitos de 1970 a 2000. MA Design. Pontíficia Universidade Católica do Rio de Janeiro, 2007. Disponível na internet por http em:_http://www.maxwell.vrac.pucrio.br/Busca_etds.php?strSecao=resultado\&nrSeq=11097@1>. Acesso em 14 Mai. 2016. 